\title{
A PENNA CONTRA A EMIGRAÇÃO
}

\author{
Ely Souza Estrela *
}

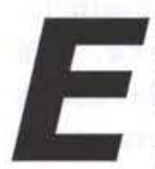
stima-se que mais de $17 \%$ das pessoas nascidas na Bahia vivem fora do estado. Desse montante não se sabe quantos vivem ao certo no estado de São Paulo. Sabe-se entretanto, que $7 \%^{1}$ vivem na região metropolitana, marcando com sua presença não somente o $\mathrm{ABC}$ paulista, mas principalmente os bairros mais periféricos da cidade de São Paulo.

A participação das regiões da Bahia no contingente populacional que se deslocou para São Paulo não é uniforme. Não se dispõe de dados atualizados sobre o número de indivíduos que partiram de cada uma das regiões do estado da Bahia em direção a São Paulo; amostragem elaborada por Antônio Jordão Neto e Santa Helena Bosco, bem como a tabela publicada por Jorge Calmon mostram que o maior número de pessoas que deram entrada na Hospedaria dos Imigrantes Visconde de Parnahyba eram provenientes das zonas fisiográficas da Serra Geral e Chapada Diamantina.

Em linhas gerais, essas regiões formam a área que, na "geografia imaginária" das comunidades sertanejas, é compreendida como alto sertão da Bahia. Esta região, juntamente com o Rio São Francisco, constituía-se em verdadeira porta de entrada/saída de população da Bahia em relação ao centro-sul do país, até mais ou menos a abertura da Rodovia Rio-Bahia, em fins da década de 1940 , e a desativação do transporte de passageiros da Viação Estrada de Ferro Leste Brasileiro - em meados da década de 80 .
Desde fins do século XIX partiam do alto sertão da Bahia levas e levas de indivíduos em direção ao centro-sul do país. Esses indivíduos eram chamados de sampauleiros. Sampauleiro era todo indivíduo que deixava seu local de origem para procurar, em terras de São Paulo, especialmente, condições de

\section{TABELA}

\section{EMIGRANTES QUE DERAM ENTRADA NA HOSPEDARIA DOS IMIGRANTES VISCONDE DE PARNAHYBA ENTRE 1935 E 1952, POR REGIÃO.}

Litoral Norte $0,4 \%$

Recôncavo.. $2,2 \%$

Zona Cacaueira $3,1 \%$

Extremo-Sul. $0,3 \%$

Nordeste $1,2 \%$

Zona de Feria de Santana $1,1 \%$

Zona de Jequié $1,8 \%$

Zona de Vitória da Conquista. $3,5 \%$

Zona de Jacobina $2,9 \%$

Zona das Matas de Orobó. $3,0 \%$

Sertão do São Francisco. $4,9 \%$

Chapada Diamantina $11,2 \%$

Serra Geral. $52,5 \%$

Médio São Francisco $6,6 \%$

Planalto Ocidental $4,4 \%$ 
dos estados de São Paulo e Mato Grosso do Sul.

A emigração dos sampauleiros preocupava as elites locais, temerosas com a virtualidade da "falta de braços". Em alguns momentos, os grupos que se opunham à emigração lançaram mão de mecanismos visando combatê-la e dificultá-la. Em 1924, o governo da Bahia, incapaz de estabelecer plano de ação de caráter mais duradouro e efetivo, com vistas a deter a evasão, sancionou uma lei, "criando o imposto de 10 cruzeiros (sic) sobre cada passagem de terceira classe vendida para fora do estado" (Calmon, 1998: 192) ${ }^{2}$.

Na cidade de Caetité, o jornal $A$ Penna, fundado por João Antônio dos Santos Gumes Júnior, foi um importante porta-voz desses grupos.

\section{Quem era João Gumes}

João Gumes foi uma das figuras mais versáteis, dinâmicas e fascinantes do alto sertão da Bahia. Nasceu em Caetité, em 10 de maio de 1858 , e morreu em 29 de abril de 1930.

Na juventude foi preceptor dos filhos de uma rica família do município de Palmas de Monte Alto, localizado às margens do Rio São Francisco. Voltando a Caetité, tornou-se escrivão da Coletoria Geral e, mais tarde, tesoureiro e secretário da Intendência do município. Foi advogado provisionado (rábula) e arquiteto. A planta do Teatro Centenário de Caetité - inaugurado em 1922 como parte das comemorações do centenário da Independência - e a do Mercado Público Municipal da cidade saíram de sua prancheta.

Foi fundador e redator do jornal $A$ Penna. Além disso, deixou vasta obra no campo das letras. Escreveu os romances Os Analphabeto e $O$ sampauleiro, as crônicas Vida campestre e Pelo Sertão e a peça A Abolição, entre outras extraviadas.

Os romances $O s$ Analphabetos e $O$ Sampauleiro abordam a emigração dos sampauleiros, retratando em pormenores o cotidiano da emigração. Curioso é que, embora Gumes fosse um obstinado combatente da partida de seus conterrâneos, a ponto de confessar que os romances eram obras de propaganda de um militante desprovido de talento literário, em nenhuma das obras se encontram laivos de oposição ao ir-e-vir dos sertanejos. Pelo contrário, em ambas, a viagem dos sampauleiros é bem-sucedida e seus protagonistas voltam à terra natal realizados. No romance $O$ Sampauleiro, o autor traça um quadro do estado de São Paulo bastante simpático. O protagonista da obra, João Lopes, é um sampauleiro honesto que, tendo pegado de empreita a abertura de uma fazenda na região de Barretos, trabalha duro, conseguindo amealhar dinheiro para saldar uma dívida contraída por artimanha de seu pseudo-amigo/rival Abílio e remontar à vida na pequena propriedade que deixara aos cuidados da esposa zelosa e fiel.

Quando criança Gumes participou do coro da igreja matriz. Adulto continuou ligado à música, participando como membro fundador da Lira Caetiteense. Consta que, além de tocar harmônica e violoncelo, fazia adaptações de partituras. Na maturidade tornou-se espírita, sendo várias vezes escolhido para a direção do "Centro de Estudos Espírita Aristides Spínola", posição que lhe trouxe alguns aborrecimentos provocados por prelados intolerantes.

\section{O pioneirismo d'A Penna}

O jornal A Penna foi fundado por João Gumes em 5 de março de 1897 e tudo indica que foi o primeiro jornal do alto sertão baiano a ter periodicidade. O jornal circulou - com algumas interrupções - até 1930, ano da morte de seu fundador. Depois de um breve interregno, voltou a ser publicado sob a direção de seu filho, Sadi Gumes. Em 1942, deixou definitivamente de circular.

A Penna era uma publicação quinzenal com quatro páginas impressas em papel jornal. Alguns números, por razões que não sabemos precisar, eram impressos em cores - azul ou rosa. Os números especiais eram impressos em papel cuchê. A grande maioria dos artigos versavam sobre temas de interesse local e regional, sendo quase todos assinados pelo editor. Gumes não se furtava a publicar também assuntos e fatos de abrangência nacional e internacional. Homens públicos da estirpe de Pedro Calmon, Anísio Teixeira e Hermes Lima, por exemplo, assinaram artigos n'A Penna. Há indícios de que alguns dos colaboradores do quinzenário nada mais eram que criação do editor, forma que encontrou para diversificar as opiniões do impresso. Aliás, com alguns dos colaboradores desconhecidos travou polêmicas, com réplicas e tréplicas acirradas.

A Penna trazia algumas seções fixas: poesias, viajantes, obituário, despedidas, "quentinhas" e, em 1940, passou a publicar a famosa "Crônica da Roça" espécie de sátira dos costumes escrita em versos, etc. À semelhança dos grandes jornais da época, tinha espaço reservado aos folhetins. Antes de serem impressos em livros, os romances $O$ Sampauleiro, Os Analphabetos e o livro de crônicas Vida campestre foram publicados no jornal.

O jornal contava com amplo espaço publicitário, suficiente para sua manutenção ${ }^{3}$. Anúncios de drogarias, de casas comerciais (secos e molhados, implementos agrícolas, vestuário) remédios, armarinhos, xaropes, saboarias, representantes comerciais eram freqüentes no jornal A Penna. Alguns dos anunciantes não estavam localizados nas praças da região, mas nas dos grandes centros, tais como, São Paulo, Rio de Janeiro e "Bahia", como os baianos do interior denominavam Salvador.

Tendo em vista as dificuldades de meios de transporte, A Penna contava com um corpo de assinantes considerado razoável para a época, transpondo, 
inclusive, os limites da região.

$\mathrm{O}$ primeiro prelo utilizado na impressão do jornal era manual (emprestado à Intendência); pouco depois, Gumes adquiriu um prelo a pedal e, em 1919, comprou por oito contos de réis uma rotativa movida manualmente. Orgulhoso do feito, o jornal estampava em primeira página o dizer: "Impresso em machina rotativa Marinoni". A vultosa soma foi adquirida através de subscrição das elites locais.

Desde o primeiro número, o jornal mostrava-se determinado a defender os interesses da alta zona sertaneja. No frontispício da primeira página (acima da chamada sobre a forma de impressão), ostentava o dizer: "Orgam dos interesses commerciais, agricolas e civilizadores do Alto Sertão" e dizia defender três propósitos: a expansão da lavoura, a ferrovia e o fim da emigração. De fato, o jornal nunca fugiu aos propósitos enunciados.

\section{O combate à emigração}

A leitura do jornal A Penna dá um quadro bastante pormenorizado do cotidiano da alta zona sertaneja da Bahia e é através dela que tomamos conhecimento da dimensão da emigração nas primeiras décadas do século XX. Com exceção da seca, a emigração foi um dos assuntos que mais ocuparam espaço n'A Penna.

Nas páginas do quinzenário, o deslocamento aparece em pormenores: a viagem penosa, a vestimenta, os meios de transporte, os casos de perturbação mental, as hospedagens, a chegada a São Paulo, o retorno, os riscos e temores, o sucesso ou insucesso da empreitada, enfim, tudo o que diz respeito à travessia era cingido com dramático realismo.

Expressando os interesses das elites econômicas (fazendeiros e comerciantes atacadistas) e políticos do alto sertão, Gumes faz do seu jornal uma espécie de trincheira contra aquilo que chama de "despovoamento do sertão", traçando um quadro das características do sampauleiro bastante desfavorável, instando a todo momento as autoridades constituídas a tomarem providências para deter a sangria das massas trabalhadoras e, ao mesmo tempo, tentando convencer esses indivíduos da necessidade de permanecerem no seu "agro de terras feracíssimas".

Quem eram os sampauleiros? Para Gumes, eram provenientes da "mais baixa camada social, (...) bahianitos ignorantes e atrazados (...)"4 que se deixavam enganar pela propaganda dos arregimentadores. Como um D. Quixote sertanejo a combater moinhos de vento não se cansava de denunciar o fascínio que São Paulo exercia sobre as populações interioranas e seus resultados maléficos. Vejamos:

"A curiosidade, a esperança de prompto enriquecimento. Muitos têm vendido os seus gados, as suas terras, lavoura e situações, onde vivia tranquila e commodamente para com esses recursos pecuniários, empreenderem a longa e extenuante viagem em busca do Eldorado: outros são aconselhados $e$ sugestionados por especuladores que fornecem-lhes dinheiro aqui com a condição de pagarem-no com $o$ peso de juro de cem por cento. (!!!); outros, ainda, são aliciados por expertos que os contracta a tanto por cabeça sob o pressuposto de lhe pagarem as despesas da viagem pela conta que lhes for apresentada."

Honesto, Gumes traçava um quadro do estado de São Paulo bastante favorável, mostrando-se, inclusive, seu entusiasta, reconhecendo a sua grandeza e pujança, mas não se esquecia de afirmar constantemente ser a viagem para São Paulo um engodo. Segundo ele, os sampauleiros nada lucravam com o trabalho nas lavouras paulistas, afirmando peremptoriamente: "ainda estamos por conhecer o indivíduo que tenha conseguido uma fortuna, mesmo relativa, nesse constante vaivém dos nossos coolie"

Do ponto de vista do editor de $A$ Penna, os sampauleiros eram explorados por agiotas, aliciadores e fazendeiros espertos, sendo praticamente impossível a concretização do sonho que os movia às terras longínquas da paulicéia: a bonança e riqueza fácil.

Explicitando melhor seu ponto de vista, o jornalista colocava em dúvida a honestidade dos poucos sampauleiros enriquecidos, mostrando os meios de que lançavam mão para amealhar as riquezas alardeadas e ostentadas nas comunidades sertanejas. Vejamos:

\begin{abstract}
"Alguns, porem, pouco escrupulosos arranjam-se bem. Apresentam-se em São Paulo com pseudonymo, dão-se de uma região da Bahia quando são de outra e, conquistando a confiança de incautos, conseguem por engenhoso conto do vigário, obter as vezes boas quantias. Não raro, outros assaltos a pedestre da sua classe que volta a Bahia trazendo quantias diversas e amassam com sangue, miseravelmente, a base de sua riqueza. Outros ainda locupletam-se com o dinheiro de que são portadores incumbidos por seus patrícios que lá ficam. Esses taes gabam-se entre nos terem enriquecidos honestamente."
\end{abstract}

$\mathrm{O}$ aliciamento de nordestinos para levar ao Centro-Sul tornou-se prática bastante conhecida no processo de desenvolvimento da economia brasileira, sendo empregado sobretudo por particulares. Era comum o aliciamento de jovens, crianças e mulheres. $\mathrm{O}$ editor do jornal A Penna estava sempre a denunciar a ação malfazeja do aliciador sobre as comunidades sertanejas, pesando sobre eles a denúncia de carregar indivíduos utilizando-se de falsas promessas e outros meios ainda mais sórdidos. João Gumes denunciava que os aliciadores ganhavam das empresas contratantes por cabeça arregimentada e que em São Paulo obrigavam os sampauleiros a "pagarem 
as despesas da viagem pela conta que lhes for apresentada".

Num rasgo de antipatia, lança mão do escárnio, da ridicularização e da ironia, denominando os sertanejos que partem da terra natal para se aventurar por terras alheias, cheias de armadilha e riscos, de sampaulomaníaco e fanáticos. Vejamos:

“(... ) Os traços de união ou laços que unem os indivíduos entre si para formarem a classe; que são comuns a todos esses infelizes a quem dá-se a denominação de SAMPAULEIROS; consistem emsugestibilidade pelas riquezas do sul; o sonhar com o futuro prospero e grandioso que foge lhes como a sua sombra uma profunda descrença das cousas e dos homens da Bahia, como os seus poderes públicos, as suas riquezas naturaes, as medidas que sejam projetadas ou mesmo tomadas entre nós e - traço physico caracteristico: - ao sahir da Bahia, um alvo sacco alceado, um caldeirão de folhas de Flandres e alpergatas dobradas de couro cru; - ao voltar, roupa e sacco imundos e terrosos; caldeirão esfumaçado, um chapeo novo de feltro de nikel e lenço de pseudo-setin em volta do pescoço à guisa de gravata e (...) O FALÁ LEEGERO. Ê APAULISTADO de quem viu e apreciou cousas novas, $e$ magnificantes."

Vez ou outra, assumia um discurso mitificador - nos fazendo lembrar "o sertanejo é antes de tudo um forte", de Euclides da Cunha -, destacando o caráter enérgico e desassombrado desses indivíduos. Assim, o sampauleiro autêntico, no dizer de João Gumes, era o indivíduo em trânsito, era o "homem forte e destemido que já tem feito reiteradas viagens ao opulento estado do Sul (...)".

Também sobre as causas da emigração a posição de Gumes é ambígua e oscilante. Em alguns artigos, percebe-se claramente que o jornalista não consegue apreendê-lo muito bem. Trata-o como se fora motivado unicamente pelo caráter doentio, errático e aventureiro do sertanejo dos mais baixos estratos sociais, bastando, portanto, ação enérgica para chamar-lhe à razão e fazê-lo parar com a errância descabida. Nesta perspectiva, os artigos que tratavam da mobilidade dos sertanejos eram carregados de clamores - eivados de impaciência - ora dirigidos aos sertanejos para que voltassem à razão e não abandonassem seu "agro feracíssimo", ora às autoridades para fazerem cessar o despovoamento do sertão. Vejamos:

"Toma proporções assustadoras a emigração de nosso povo para São Paulo. A princípios eram levas $e$ levas de centenares trabalhadores que seguiam deixando as famílias; agora passam por aqui e por muitos outros pontos centenares de familias, homens, mulheres, crianças, velhos, novos e estropiados conduzido tudo o que possuem. É uma febre, uma epidemia, uma loucura que não se justifica que não se levantou e matem por uma causa justa. Bem sabemos que o cidadão é livre de locomoverse como quizer, firmar a sua residencia onde bem lhe parecer; mas as consequencias serão terríveis para todos esses fanáticos e para a lavoura já tão depauperada. Pedimos $e$ instamos serias providencias. Aos collegas imploramos que dêm o rebate $e$ procurem convencer, com melhores argumentos, a quem de direito, da urgente necessidade de remediar a nossa situação."

Em outros artigos, deixa transparecer que a mobilidade espacial é irreversível, servindo de válvula de escape aos problemas seculares da região e, diante da insensibilidade e do silêncio das autoridades baianas em relação à questão, passa a vê-la com mais objetividade. Continua a clamar contra o deslocamento, a denunciar seus malefícios à alta zona sertaneja, a incitar aos emigrantes que permaneçam cuidando de seus pertences, a regozijarse toda vez que tem notícia do retorno dos sampauleiros, mas não deixa de reconhecer que suas causas estão relacionadas às questões de ordem socioeconômicas e políticas, rebatendo, inclusive, as posições que vêem as secas como molas propulsoras do fenômeno migratório.

"O que tem desanimado nosso agricultor constragendo-o a procurar o Estado de São Paulo éo dilema da extrema carestia e penuria nos excepcionais annos de secca $e$ da extrema desvalorização dos produtos agricolas nos annos abundantes. O phenomeno é digno de um sério estudo por parte das classes dirigentes do nosso Estado, que é sacudido em toda sua extensão, nos seus interesses economicos $e$ financeiros, por esse estado de cousas."

E em diversos outros artigos, Gumes denuncia o abandono, o "atraso" (grifo da autora) e a violência que vigoravam no alto sertão como molas propulsoras da mobilidade espacial.

Nos anos de 1920-30, em alguns municípios da Chapada Diamantina e do Médio São Francisco, a violência perpetrada por coronéis em disputa punha em pânico a população de ambas as regiões, ganhando, inclusive, espaço nas publicações dos grandes centros. $A$ Penna noticiava farto material dando conta do abandono de cidades sertanejas por parte de sua população. Assim, João Gumes não se cansava de denunciar a violência como uma das principais motivadoras do "despovoamento" da alta zona sertaneja, nas primeiras décadas do século. Sobre a questão, escreve:

"E que um mal esta pesando sobre a infeliz região, onde o trabuco toma a dianteira à foice, à enxada, onde a caudilhagem desabusada pede meças ao bolchevismo e uma como 
avalanche ameaçadora vae lentamente inundando, transvertendo os nossos costumes, precipitando-nos em um estado de ruína que dificilmente poderá ser remediado. Isso por um lado, o fisco com as suas garras aduncas por outro, o serviço militar obrigatório por outro, a insegurança do proprietários rural; tudo isso, junta a falta de meios de transporte para os nossos productores afugenta os pacíficos e honestos que temem os incômodos e perigos que as presentes luctas cream, alimentame robustecem para o gaudio de poucos."

Mais adiante, revelando extrema lucidez, Gumes rebate o ponto de vista dos que afirmam ser a emigração provocada pela seca e pela fome. $\mathrm{Na}$ sua opinião, as causas da emigração devem ser buscadas no descontentamento da população sertaneja em relação ao descaso com que sempre foi tratada pelas autoridades constituídas e, ao mesmo tempo, na descrença dos valores e nas lideranças da região. Vejamos:

\section{(...) E a descrença em nossas cousa} em nossos homens; são a fome e a sede de justiça, de tranquilidade, de emancipação. Tantas e tantas vezes nos promettem, aqueles de que depende a direção de nossa sociedade, dotar-nos de meios de transportes para depois deixar-nos clausos em indefinidas esperanças; - tantas vezes nos acenaram com fallazes promessas de melhoras, para depois rirem a socapa da nossa ingenuidade; - tanto têm baixado o nível a aplicação do direito e da justiça, o respeito à propriedade, à honra, à dignidade e as regalias do cidadão; - tanto têm sido conculcados os mais sagrados princípios que foram-nos outhorgados, não pelas leis humanas, mas pelo Princípio Eterno e Soberano que nos cercou; - tanto temos sido e somos explorados por poucos que vivem à farta zombando impiedosamente do rebanho de servos da gleba, já estanguidos pelas retiradas tosquias e votadas, em sua imortalidade e indiferença, a servir somente de pretextos aos simulados comícios; - que, afinal lavra a descrença à feição de epidemia e vae tomando caracter endemico."

Em que pesem as denúncias e os clamores de João Gumes, os sampauleiros continuaram no seu "vaie-vem". Afinal, nas primeiras décadas do século XX, o alto sertão da Bahia passa a ser entendido como o espaço das carências, incapaz, portanto, de atender às expectativas de mudança, verificadas em São Paulo. Essa incapacidade resulta basicamente de três fatores: a estrutura da propriedade da terra que se torna bastante polarizada em latifúndios e minifúndios; as freqüentes secas que desagregam o sistema comunitário de vida; e a falta de recursos técnicocientíficos.

Em contraposição à alta zona sertaneja - mundo considerado atrasado e "pasmacento" - São Paulo era vista, de modo geral, como o lugar da abundância de emprego, de melhores salários, de perspectiva de melhoria de vida, de acesso à educação, de desenvolvimento técnico-científico, enfim, representava o novo e a "modernidade" e "onde dinheiro era mato".

* Ely Souza Estrela é Prof ${ }^{a}$. do Dpto. de Ciências Humanas de Caetité Universidade do Estado da Bahia.

\section{NOTAS}

1 - Fundação Seade, Folha de São Paulo, 2/3/1996.

2 - A disputa por mão-de-obra entre paulistas e nordestinos remonta ao período do tráfico interno de escravos. Naquele momento, as elites nordestinas, especialmente os baianos, combateram com virulência o carreamento de sua força de trabalho para as zonas cafeeiras de São Paulo. O combate se travou basicamente pelo uso de pesadas taxações para cada escravo exportado. Tal medida provocou da parte das autoridades paulistas contra-ataque, que consistia na diminuição das tarifas de importação de escravos, minimizando os efeitos do aumento tarifário empreendido pelo governo baiano. (Jornal $A$ Penna 14/03/1915).

3 - Maurício Gumes. Entrevista tomada pela autora em Caetité, em 12/4/2002. Todos os dados foram confirmados por Silvio Gumes Fernandes, em entrevista tomada em Caetité (9/05/2002).

4 - A grafia das palavras está de acordo com o original.

\section{REFERÊNCIAS BIBLIOGRÁFICAS}

\section{BEOZZO, Pe. José Oscar}

(1992) Brasil: 500 anos de migrações. São Paulo, Paulinas.

Bosco, Santa Helena \& JORDÃO NETO, Antônio

(1967) Migrações: estudo especial sobre as migrações internas para o Estado de São Paulo e seus efeitos. São Paulo,

Secretaria da Agricultura do Estado de São Paulo.

CALMON, Jorge

(1998) As estradas corriam para o Sul. Migração nordestina para São Paulo. Salvador, Editora Gráfica da Bahia, p.208.

DURHAM, Eunice

(1973) A caminho da cidade: a vida rural e a migração para São Paulo. São Paulo, Perspectiva.

ESTRELA, Ely Souza

(1998) "Os Sampauleiros - Memória do Deslocamento". Travessia-Revista do Migrante, $n^{2} 32$, set-dez., pp. 11-13.

GUMES, Marieta Lobão

(1975) O clã dos Neves. Salvador, Editora Mensageiro da Fé.

NEVES, Flávio

(1986) Rescaldo de Saudades. Belo Horizonte, Academia Mineira de Medicina.

SANTOS, Helena

(1976) Caetité, pequenina e ilustre. Salvador, Gráfica Nossa Senhora de Loreto.

GUMES, João

(1928) Os analfhabetos. Salvador, Escola Typographica Salesiana.

GUMES, João

(1929) O Sampauleiro. Caetité, Tipographia d' A Penna. 